\title{
Pemilihan Supplier Sparepart Tetap di PT. Mitra Wahyu Prakasa
}

\author{
Trisna Mesra ${ }^{1}$, Surya Indrawan ${ }^{2}$, Nur Irfan ${ }^{3}$ \\ 1,2,3)Program Studi Teknik Industri Sekolah Tinggi Teknologi Dumai \\ Jl. Utama Karya Bukit Batrem II \\ Email: trisnamesra74@gmail.com
}

\begin{abstract}
ABSTRAK
Salah satu untuk menjaga kualitas suatu produk dengan cara menentukan supplier yang mampu memberikan bahan baku yang berkualitas, agar mendapatkan kriteria supplier yang mampu memenuhi kebutuhan perusahaan secara konsisten dan berkelanjutan. Berdasarkan masalah tersebut, penulis melakukan penelitian menggunakan metode AHP (Analytical Hierarchy Process) untuk studi kasus Pemilihan Supplier Spareparts tetap di PT Mitra Wahyu Prakasa. Penggunaan metode ini mampu memberikan nilai pada masing-masing kriteria dan alternatif pilihan. Adapun kriteria yang ditetapkan dalam pemilihan supplier ini adalah kriteria Pengiriman, Kriteria Kualitas, kriteria Garansi dan kriteria Harga, dengan alternatif pilihan PT A Maju Jaya, PT C Sukses Abadi Motor dan PT C Sahabat Banindo. Berdasarkan hasil penelitian yang dilakukan didapat nilai dari masingmasing kriteria, Pengiriman 0.52, Kualitas 0.18, Garansi 0.18, dan Harga 012. Sedangkan nilai alternatif berdasarkan kriteria PT A 0.31, PT B 0.22, dan PT C 0.47. Berdasarkan hasil di atas, maka PT C terpilih sebagai supplier sparepart di PT Mitra Wahyu Prakasa dengan nilai 0.47. dan kriteria Pengiriman terpilih menjadi kriteria yang paling berpengaruh dengan nilai 0.52 .
\end{abstract}

Kata kunci: AHP, Supplier, Teori keputusan.

\begin{abstract}
One is to maintain the quality of a product by determining the suppliers who are able to provide quality raw materials, in order to obtain the criteria of suppliers who are able to meet the company's needs consistently and continuously. Based on these problems, the authors conducted a study using the AHP (Analytical Hierarchy Process) method for a case study of the selection of fixed spare parts suppliers at PT Mitra Wahyu Prakasa. The use of this method is able to provide value for each criterion and alternative choices. The criteria set out in the selection of suppliers are Shipping criteria, Quality Criteria, Warranty criteria and Price criteria, with alternative choices of PT A Maju Jaya, PT C Sukses Abadi Motor and PT C Sahabat Banindo. Based on the results of the research conducted obtained the value of each criterion, Delivery 0.52, Quality 0.18, Warranty 0.18, and Price 012. While the alternative value is based on the criteria of PT A 0.31 , PT B 0.22, and PT C 0.47. Based on the results above, PT C was chosen as a spare parts supplier at PT Mitra Wahyu Prakasa with a value of 0.47 . And the Delivery criteria selected are the most influential criteria with a value of 0.52
\end{abstract}

Keywords: AHP, Supplier, Decision theory.

UNITEK Vol 12 No.1 Januari - Juni 2019 | p-ISSN 2089-3957 | e-ISSN 2580-2585 


\section{Pendahuluan}

Salah satu cara untuk menjaga mutu dan kualitas dari produk itu dengan cara pemilihan supplier yang mampu memberikan bahan baku yang berkualitas. Pemilihan ini dilakukan untuk mendapatkan kriteria supplier yang mampu memenuhi kebutuhan perusahaan secara konsisten dan berkelanjutan. Kualitas produk dan harga menjadi suatu persaingan bagi para penyedia produk. Pemilihan supplier bagi perusahaan adalah hal yang paling utama, karena jika sampai salah memilih supplier, kinerja perusahaan pun akan berpengaruh, bisa jadi perusahaan mengalami kebangkrutan akibat adanya pengeluaran dan pemasukan perusahaan yang tidak sebanding.

Penelitian ini diselesaikan dengan menggunakan metode (Analytical Hierarchy Process). AHP ialah metode yang membantu memecahkan persoalan yang kompleks dengan menstruktur suatu hirarki kriteria, pihak yang berkepentingan, hasil dan dengan menarik berbagai pertimbangan guna mengembangkan bobot atau prioritas. Hal ini membuat peneliti ingin mengetahui supplier mana yang terbaik untuk PT MWP sehingga nantinya dijadikan sebagai supplier sparepart tetap nya.

\section{Metode Penelitian}

Penelitian ini dilakukan di PT Mitra Wahyu Prakasa yang mana populasi dalam penelitian ini adalah seluruh karyawan PT Mitra Wahyu Prakasa yang berjumlah 40 orang. Sementara itu untuk sampel dalam penelitian ini adalah seluruh jumlah yang ada pada populasi. dari bagian manager teknik dan finance sebanyak 10 orang, manager marketing 10 orang dan operator armada angkutan sebanyak 20 orang. Jenis dan Sumber data yang digunakan pada penelitian ini terdiri dari data primer dan data sekunder. Data primer dalam penelitian ini diperoleh dari kuesioner yang diisi oleh responden, meliputi: identitas dan tanggapan responden tentang pemilihan supplier yang terbaik. Data sekunder diperoleh dari literatur, internet, jurnal dan sumber lainnya yang berkaitan erat dengan penelitian ini.

Untuk mendapatkan kelengkapan informasi yang sesuai dengan penelitian menggunakan teknik pengumpulan data adalah sebagai berikut:

1. Kuesioner, Penelitian ini menggunakan beberapa pertanyaan yang diajukan kepada pengisi kuesioner.

2. Kepustakaan, Peneliti mencari referensi serta mempelajari jurnal dan literature lainnya yang berhubungan dengan tugas akhir ini.

Penelitian ini pengolahan data menggunakan metode analysis hierarchy process (AHP) yang terdiri dari pengumpulan data, membuat perbandingan berpasangan, menghitung nilai tingkat kepentingan, mencari rata rata dari tingkat kepentingan, mencari lamda maks, mencari konsistensi indeks, menghitung konsistensi rasio, dan menentukan alternatif supplier terbaik untuk dipilih sebagai supplier menjadi langganan (Rimantho, dkk, 2017).

Teknik analisis data pada penelitian ini dilakukan setelah data kuesioner dikumpulkan dan dilakukan pengolahan data menggunakan metode analysis

UNITEK Vol 12 No.1 Januari - Juni 2019 | p-ISSN 2089-3957 | e-ISSN 2580-2585 
hierarchy process (AHP) untuk menentukan pilihan terbaik dari beberapa alternatif supplier dengan pertimbangan kriteria-kriteria yang ditentukan sebagai pertimbangan dalam pemilihan supplier (Rimantho, dkk, 2017). Diagram berikut mempresentasikan keputusan untuk memilih supplier spareparts, dengan menggunakan AHP. Adapun kriteria untuk membuat keputusan tersebut adalah, pegiriman, kualitas, garansi dan harga beserta dengan alternatif pilihan PT A (Maju Jaya), PT B (Sukses Abadi Motor) dan PT C (Sukses Abadi Motor). Hierarki persoalan ini dapat dilihat pada Gambar 1.

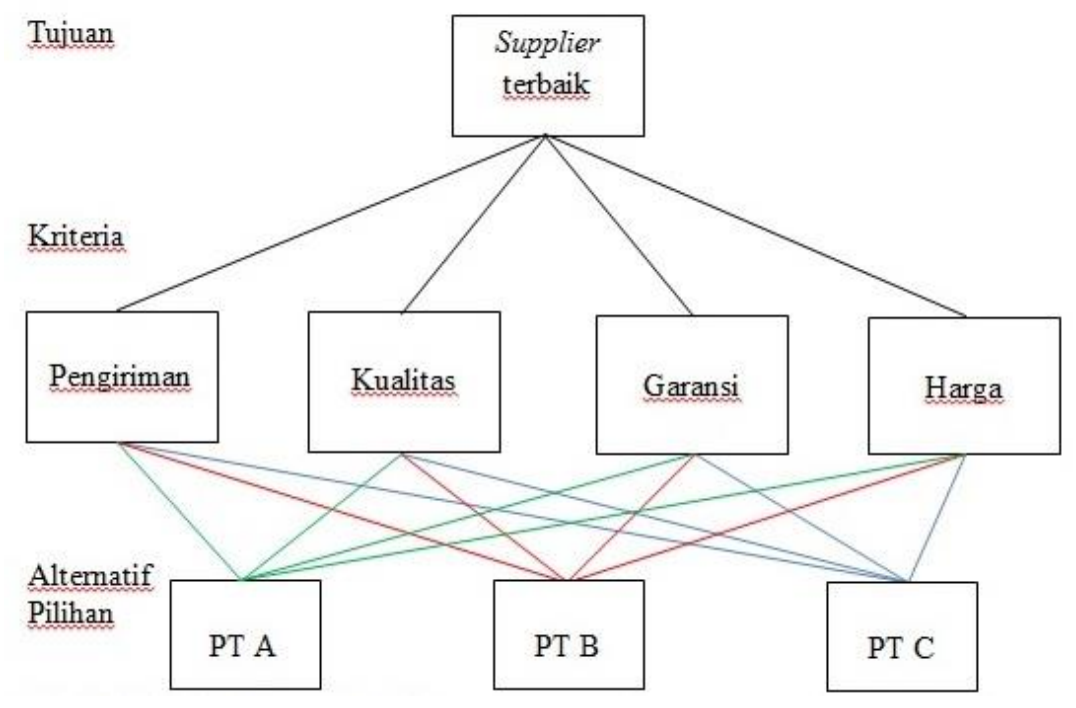

Gambar 1. Struktur hierarchy

Tujuan dari pembuatan struktur hierarchy ini adalah untuk membantu menentukan supplier spareparts tetap di PT Mitra Wahyu Prakasa. Dengan kriteria pilihan pengiriman, kualitas, garansi dan harga.

\section{Hasil dan Pembahasan}

Pengumpulan data melalui penyebaran kuesioner kepada seluruh karyawan yang bekerja di PT Mitra Wahyu Prakasa.

\section{Perhitungan Kriteria}

Adapun perhitungan dari perbandingan beberapa kriteria pengiriman, kualitas, garansi dan pengiriman dapat dilihat pada Tabel 1.

Tabel 1. Perbandingan berpasangan kriteria

\begin{tabular}{|l|c|c|c|c|}
\hline \multicolumn{1}{|c|}{ Kriteria } & Pengiriman & Kualitas & Garansi & Harga \\
\hline Pengiriman & 1.00 & 2.15 & 3.40 & 5.01 \\
\hline Kualitas & 0.46 & 1.00 & 0.76 & 1.36 \\
\hline Garansi & 0.29 & 1.31 & 1.00 & 1.41 \\
\hline
\end{tabular}

UNITEK Vol 12 No.1 Januari - Juni 2019

| p-ISSN 2089-3957 | e-ISSN 2580-2585 


\begin{tabular}{|l|l|l|l|l|} 
Harga & 0.20 & 0.73 & 0.71 & 1.00 \\
\hline Jumlah & 1.96 & 5.20 & 5.87 & 8.78 \\
\hline
\end{tabular}

Setelah membuat perbandingan berpasangan dilanjutkan normalisasi perbandingan berpasangan untuk setiap kriteria dapat dilihat pada Tabel 2.

Tabel 2. Normalisasi Perbandingan Berpasangan Kriteria

\begin{tabular}{|l|c|c|c|c|c|}
\hline \multicolumn{1}{|c|}{ Kriteria } & Pengiriman & Kualitas & Garansi & Harga & Jumlah \\
\hline Pengiriman & 0.51 & 0.41 & 0.58 & 0.57 & 2.07 \\
\hline Kualitas & 0.24 & 0.19 & 0.13 & 0.16 & 0.71 \\
\hline Garansi & 0.15 & 0.25 & 0.17 & 0.16 & 0.73 \\
\hline Harga & 0.10 & 0.14 & 0.12 & 0.11 & 0.48 \\
\hline
\end{tabular}

Setelah melakukan perhitungan perbandingan kriteria selanjutnya mencari ratarata dan $\lambda$ dari tiap kriteria yang telah dihitung.

Tabel 3. Rata- Rata dan $\lambda$ Kriteria

\begin{tabular}{|l|c|c|}
\hline \multicolumn{1}{|c|}{ Kriteria } & Rata- Rata & Lamda $(\mathrm{\lambda})$ \\
\hline Pengiriman & 0.52 & 1.02 \\
\hline Kualitas & 0.18 & 0.93 \\
\hline Garansi & 0.18 & 1.08 \\
\hline Harga & 0.12 & 1.05 \\
\hline Jumlah & 1.00 & 4.07 \\
\hline
\end{tabular}

Pada Tabel 3 diketahui rata- rata dan $\lambda$ selanjutnya mencari $\lambda$ maks dengan cara menjumlahkan semua nilai $\lambda$ dari kriteria pengiriman, kualitas, garansi dan harga dengan hasil 4.07. Uji Konsistensi Indeks dan Rasio atau CI (Consistency Index) dan CR (Consistency Ratio) Perbandingan Berpasangan Kriteria. Saaty telah membuktikan bahwa Indeks Konsistensi (consistency index, CI) dapat diperoleh dengan menggunakan Rumus:

$$
\mathrm{CI}=\frac{4.07-4}{4-1}=0.02329
$$

Mencari CR (Consistency Ratio) menggunakan Rumus:

$$
\mathrm{CR}=\frac{0.02329}{0.9}=0.02588
$$

Berdasarkan perhitungan didapat nilai 0.02588 dan kecil dari 10\% maka nilai CR dianggap memenuhi syarat.

\section{Perhitungan Alternatif}

a. Perbandingan alternatif berdasarkan kriteria Pengiriman

UNITEK Vol 12 No.1 Januari - Juni 2019 | p-ISSN 2089-3957 | e-ISSN 2580-2585 
Adapun perbandingan alternatif berdasarkan kriteria Pengiriman menggunakan perhitungan rata-rata geometri dapat dilihat pada Tabel 4.

Tabel 4. Perbandingan alternatif berdasarkan kriteria pengiriman

\begin{tabular}{|l|c|c|c|}
\hline Alternatif & PT A & PT B & PT C \\
\hline PT A & 1.00 & 1.13 & 0.26 \\
\hline PT B & 0.88 & 1.00 & 0.18 \\
\hline PT C & 3.82 & 5.57 & 1.00 \\
\hline Jumlah & 5.71 & 7.70 & 1.44 \\
\hline
\end{tabular}

Setelah membuat perbandingan berpasangan alternatif berdasarkan kriteria Pengiriman dilanjutkan normalisasi perbandingan berpasangan yang dapat dilihat pada Tabel 5 .

Tabel 5. Normalisasi perbandingan alternatif berdasarkan kriteria pengiriman

\begin{tabular}{|l|c|c|c|c|}
\hline Alternatif & PT A & PT B & PT C & Jumlah \\
\hline PT A & 0.18 & 0.15 & 0.18 & 0.50 \\
\hline PT B & 0.15 & 0.13 & 0.12 & 0.41 \\
\hline PT C & 0.67 & 0.72 & 0.69 & 2.09 \\
\hline
\end{tabular}

Setelah melakukan perhitungan perbandingan kriteria selanjutnya mencari ratarata dan $\lambda$ dari tiap alternatif kriteria pengiriman dilihat pada Tabel 6 .

Tabel 6. Rata- Rata dan $\lambda$ alternatif berdasarkan krtieria pengiriman

\begin{tabular}{|l|c|c|}
\hline Alternatif & Rata-Rata & Lamda $(\lambda)$ \\
\hline PT A & 0.17 & 0.96 \\
\hline PT B & 0.14 & 1.05 \\
\hline PT C & 0.7 & 1.00 \\
\hline Jumlah & 1.01 & 3.01 \\
\hline
\end{tabular}

Pada Tabel 6 diketahui rata- rata dan $\lambda$ selanjutnya mencari $\lambda$ maks dengan cara menjumlahkan semua nilai $\lambda$ dari kriteria pengiriman, kualitas, garansi dan harga dengan hasil 3.01.

a. Uji Konsistensi Indeks dan Rasio atau CI (Consistency Index) dan CR (Consistency Ratio) Perbandingan Kriteria Pengiriman. Saaty telah membuktikan bahwa Indeks Konsistensi (consistency index, CI) dapat diperoleh dengan menggunakan Rumus:

$$
\mathrm{CI}=\frac{3.01-3}{3-1}=0.00567
$$

Mencari CR menggunakan Rumus: 


$$
\mathrm{CR}=\frac{0.00567}{0.58}=0.00978
$$

Berdasarkan perhitungan didapat nilai 0.00978 dan kecil dari 10\% maka nilai CR dianggap memenuhi syarat.

b. Perbandingan alternatif berdasarkan kriteria Kualitas

Adapun perbandingan alternatif berdasarkan kriteria Kualitas dengan menggunakan perhitungan rata-rata geometri pada Tabel 7 .

Tabel 7. Perbandingan Alternatif Berdasarkan Kriteria Kualitas

\begin{tabular}{|l|c|c|c|}
\hline Alternatif & PT A & PT B & PT C \\
\hline PT A & 1.00 & 0.81 & 2.52 \\
\hline PT B & 1.23 & 1.00 & 2.92 \\
\hline PT C & 0.40 & 0.34 & 1.00 \\
\hline Jumlah & 2.63 & 2.16 & 6.44 \\
\hline
\end{tabular}

Setelah membuat perbandingan berpasangan alternatif berdasarkan kriteria kualitas dilanjutkan normalisasi perbandingan berpasangan yang dapat dilihat pada Tabel 8.

Tabel 8. Normalisasi perbandingan alternatif berdasarkan kriteria kualitas

\begin{tabular}{|l|c|c|c|c|}
\hline Alternatif & PT A & PT B & PT C & Jumlah \\
\hline PT A & 0.38 & 0.38 & 0.39 & 1.15 \\
\hline PT B & 0.47 & 0.46 & 0.45 & 1.39 \\
\hline PT C & 0.15 & 0.16 & 0.16 & 0.47 \\
\hline
\end{tabular}

Setelah melakukan perhitungan perbandingan kriteria selanjutnya mencari ratarata dan $\lambda$ dari alternatif berdasarkan kriteria kualitas dilihat pada Tabel 9.

Tabel 9. Rata- Rata dan $\lambda$ Alternatif Berdasarkan Krtieria Kualitas

\begin{tabular}{|l|c|c|}
\hline Alternatif & Rata-Rata & Lamda $(\lambda)$ \\
\hline PT A & 0.38 & 1.01 \\
\hline PT B & 0.46 & 1 \\
\hline PT C & 0.16 & 1 \\
\hline Jumlah & 1.00 & 3.00 \\
\hline
\end{tabular}

Pada Tabel 9 diketahui rata- rata dan $\lambda$ selanjutnya mencari $\lambda$ maks dengan cara menjumlahkan semua nilai $\lambda$ kriteria pengiriman, kualitas, garansi dan harga dengan hasil dengan hasil 3.00.

a. Uji Konsistensi Indeks dan Rasio atau CI (Consistency Index) dan CR (Consistency Ratio) Perbandingan Kriteria Kualitas.

UNITEK Vol 12 No.1 Januari - Juni 2019 | p-ISSN 2089-3957 | e-ISSN 2580-2585 
Saaty telah membuktikan bahwa Indeks Konsistensi (consistency index, CI) dapat diperoleh dengan menggunakan Rumus:

$$
\mathrm{CI}=\frac{3.00-3}{3-1}=0.000234
$$

Mencari CR menggunakan Rumus 2.2.

$$
\mathrm{CR}=\frac{0.000234}{0.58}=0.0004
$$

Berdasarkan perhitungan didapat nilai 0.0004 dan kecil dari $10 \%$ maka nilai CR dianggap memenuhi syarat.

b. Perbandingan alternatif berdasarkan kriteria Garansi

Adapun perbandingan alternatif berdasarkan kriteria Garansi dengan menggunakan perhitungan rata-rata geometri dapat dilihat pada Tabel 10.

Tabel 10. Perbandingan alternatif berdasarkan kriteria garansi

\begin{tabular}{|l|r|r|r|}
\hline Alternatif & PT A & \multicolumn{1}{|l|}{ PT B } & \multicolumn{1}{l|}{ PT C } \\
\hline PT A & 1.00 & 2.76 & 2.91 \\
\hline PT B & 0.36 & 1.00 & 1.21 \\
\hline PT C & 0.34 & 0.82 & 1.00 \\
\hline Jumlah & 1.71 & 4.58 & 5.12 \\
\hline
\end{tabular}

Setelah membuat perbandingan berpasangan alternatif berdasarkan kriteria garansi dilanjutkan normalisasi perbandingan berpasangan yang dapat dilihat pada Tabel 11.

Tabel 11. Normalisasi perbandingan alternatif berdasarkan kriteria garansi

\begin{tabular}{|l|c|c|c|c|}
\hline Alternatif & PT A & PT B & PT C & Jumlah \\
\hline PT A & 0.59 & 0.60 & 0.57 & 1.76 \\
\hline PT B & 0.21 & 0.22 & 0.24 & 0.67 \\
\hline PT C & 0.20 & 0.18 & 0.20 & 0.58 \\
\hline
\end{tabular}

Setelah melakukan perhitungan perbandingan kriteria selanjutnya mencari ratarata dan $\lambda$ dari tiap alternatif berdasarkan kriteria garansi dapat dilihat pada Tabel 12 .

Tabel 12. Rata- rata dan $\lambda$ alternatif berdasarkan krtieria garansi

\begin{tabular}{|l|c|c|}
\hline \multicolumn{1}{|c|}{ Alternatif } & Rata-Rata & Lamda $(\lambda)$ \\
\hline PT A & 0.59 & 1 \\
\hline PT B & 0.22 & 1.02 \\
\hline PT C & 0.19 & 0.98 \\
\hline Jumlah & 1.00 & 3.00 \\
\hline
\end{tabular}

UNITEK Vol 12 No.1 Januari - Juni 2019 | p-ISSN 2089-3957 | e-ISSN 2580-2585 
Pada Tabel 12 diketahui rata- rata dan $\lambda$ selanjutnya mencari $\lambda$ maks dengan cara menjumlahkan semua nilai $\lambda$ dari kriteria pengiriman, kualitas, garansi dan harga dengan hasil 3.00.

a. Uji Konsistensi Indeks dan Rasio atau CI (Consistency Index) dan CR (Consistency Ratio) Perbandingan Kriteria Kualitas.

Saaty telah membuktikan bahwa Indeks Konsistensi (consistency index, CI) dapat diperoleh dengan menggunakan Rumus:

$$
\mathrm{CI}=\frac{3.00-3}{3-1}=0.001378
$$

Mencari CR menggunakan Rumus:

$$
\mathrm{CR}=\frac{0.001378}{0.58}=0.00238
$$

Berdasarkan perhitungan didapat nilai 0.00238 dan kecil dari 10\% maka nilai CR dianggap memenuhi syarat.

b. Perbandingan alternatif berdasarkan kriteria Harga

Adapun perbandingan alternatif berdasarkan kriteria Harga dengan menggunakan perhitungan rata-rata geometri dapat dilihat pada Tabel 13.

Tabel 13. Perbandingan alternatif berdasarkan kriteria harga

\begin{tabular}{|l|c|c|c|}
\hline \multicolumn{1}{|c|}{ Alternatif } & PT A & PT B & PT C \\
\hline PT A & 1.00 & 1.78 & 0.76 \\
\hline PT B & 0.56 & 1.00 & 0.71 \\
\hline PT C & 1.32 & 1.40 & 1.00 \\
\hline Jumlah & 2.88 & 4.19 & 2.47 \\
\hline
\end{tabular}

Setelah membuat perbandingan berpasangan alternatif berdasarkan kriteria harga dilanjutkan normalisasi perbandingan berpasangan yang dapat dilihat pada Tabel 14.

Tabel 14. Normalisasi Perbandingan Alternatif Berdasarkan Kriteria Harga

\begin{tabular}{|l|c|c|c|c|}
\hline \multicolumn{1}{|c|}{ Alternatif } & PT A & PT B & PT C & Jumlah \\
\hline PT A & 0.35 & 0.43 & 0.31 & 1.08 \\
\hline PT B & 0.19 & 0.24 & 0.29 & 0.72 \\
\hline PT C & 0.46 & 0.34 & 0.41 & 1.20 \\
\hline
\end{tabular}

Setelah melakukan perhitungan perbandingan kriteria selanjutnya mencari ratarata dan $\lambda$ dari tiap alternatif berdasarkan kriteria harga dapat dilihat pada Tabel 15 . 
Tabel 15. Rata- rata dan $\lambda$ alternatif berdasarkan krtieria harga

\begin{tabular}{|l|c|c|}
\hline \multicolumn{1}{|c|}{ Alternatif } & Rata-Rata & Lamda $(\lambda)$ \\
\hline PT A & 0.36 & 1.04 \\
\hline PT B & 0.24 & 1.01 \\
\hline PT C & 0.4 & 0.99 \\
\hline Jumlah & 1.00 & 3.04 \\
\hline
\end{tabular}

Pada Tabel 15 diketahui rata- rata dan $\lambda$ selanjutnya mencari $\lambda$ maks dengan cara menjumlahkan semua nilai $\lambda$ dari kriteria pengiriman, kualitas, garansi dan harga dengan hasil 3.04.

a. Uji Konsistensi Indeks dan Rasio atau CI (Consistency Index) dan CR (Consistency

Ratio) Perbandingan Kriteria Kualitas.

Saaty telah membuktikan bahwa Indeks Konsistensi (consistency index, CI) dapat diperoleh dengan menggunakan Rumus:

Mencari CI menggunakan Rumus:

$$
\mathrm{CI}=\frac{3.03-3}{3-1}=0.015581
$$

Mencari CR menggunakan Rumus 2.2.

$$
\mathrm{CR}=\frac{0.015581}{0.58}=0.02686
$$

Berdasarkan perhitungan didapat nilai 0.02686 dan kecil dari 10\% maka nilai CR dianggap memenuhi syarat.

\section{Matrik Pendapat Gabungan}

Nilai CR (Consistency Ratio) kriteria pengiriman, kualitas, garansi, harga dan alternatif pilihan PT A, PT B, dan PT C menunjukkan bahwa semua penilaian yang dilakukan secara konsisten dan hasil pembobotan dapat diterima berdasarkan konsistensi pengisian kuesionernya, karena nilai CR kecil dari 0,1 atau $<10 \%$.

Selanjutnya melakukan perhitungan matrik pendapat gabungan yang dapat dilihat pada Tabel 16 .

Tabel 16. Matrik pendapat gabungan

\begin{tabular}{|l|c|c|c|c|c|c|}
\hline \multirow{2}{*}{ Tujuan } & \multicolumn{5}{|c|}{ KRITERIA } & \multirow{2}{*}{ Bobot } \\
\cline { 2 - 5 } & Pengiriman & Kualitas & Garansi & Harga & Peringkat \\
\cline { 2 - 5 } & 0.52 & 0.18 & 0.18 & 0.12 & \\
\hline Maju Jaya & 0.17 & 0.38 & 0.59 & 0.36 & 0.31 & 2 \\
\hline $\begin{array}{l}\text { Sukses Abadi } \\
\text { Motor }\end{array}$ & 0.14 & 0.46 & 0.22 & 0.24 & 0.22 & 3 \\
\hline $\begin{array}{l}\text { Sahabat } \\
\text { Banindo }\end{array}$ & 0.70 & 0.16 & 0.19 & 0.40 & 0.47 & 1 \\
\hline
\end{tabular}

UNITEK Vol 12 No.1 Januari - Juni 2019 | p-ISSN 2089-3957 | e-ISSN 2580-2585 
Dari Tabel 16 diketahui bahwa nilai akhir dapat dilihat bahwa PT C (Sahabat Banindo) memperoleh nilai akhir paling besar dan menempati peringkat ke-1 dengan nilai 0.47, kemudian PT A Maju Jaya pada peringkat ke-2 dengan nilai 0.31, dan PT B (Sukses Abadi Motor) pada peringkat ke-3 atau terakhir dengan nilai akhir 0.22. Dari hasil perhitungan nilai masing-masing alternatif di atas terlihat bahwa tidak ada perbedaan nilai yang signifikan yang diperoleh. Hal ini dikarenakan penilaian yang diberikan oleh responden bersifat keputusan sepihak. Hal tersebut dapat dilihat dari pemberian bobot yang dimana responden lebih mementingkan kriteria pengiriman dari pada kriteria lainnya yaitu kualitas, garansi dan harga. Karena perusahaan bersifat continue maka jelas bahwa responden lebih memprioritaskan kriteria pengiriman yaitu berupa Spareparts untuk memenuhi kebutuhan perusahaan. Sehingga dalam hal ini perusahaan tidak akan mengalami keterlambatan jika armada angkutan mengalami kerusakan akan cepat ditangani dengan ketersediaan spareparts. Hasil ini sesuai dengan penelitian yang dilakukan oleh Ngatwi dan Setyaningsih pada tahun 2011 yang menyatakan bahwa penentuan kriteria dan alternatif yang terpilih berdasarkan bobot nilai yang paling tinggi.

\section{Simpulan}

Kesimpulan yang dapat penulis simpulkan dalam penelitian ini adalah sebagai berikut:

1. Supplier yang terpilih menjadi pemasok sparepart tetap di PT Mitra Wahyu Prakasa adalah PT Sahabat Banindo dengan bobot nilai 0,47. Sedangkan PT Maju Jaya berada di urutan kedua dengan bobot nilai $(0,31)$ dan PT B Sukses Abadi Motor di urutan ketiga dengan bobot nilai $(0,22)$.

2. Kriteria yang paling berpengaruh dalam pemilihan alternatif adalah kriteria Pengiriman dengan nilai 0,52.

\section{Daftar Pustaka}

Astute, P., (2016). Pengaruh Supplier Bahan Baku Dengan Metode AHP Study Kasus PT Nara Summit Industry. Jurnal Teknologi Informasi dan Komunikasi, 7(1).

Hayati, E, N., (2014). Supply Chain Management (SCM) dan Logistic Management. Jurnal Dinamika Teknik, 8(1), 25-34.

Kurniawati, D., Yuliando, H., dan Widodo, K, H., (2013). Kriteria Pemilihan Pemasok Menggunakan Analytical Network Procces. Jurnal Teknik Industri, 15(1).

Marimin. (2015). Pengambilan Keputusan Kriteria Majemuk. Jakarta: Grasindo.

Ngatwi., \& Setyaningsih, I., (2011). Analisis Pemilihan Supplier Menggunakan Metode Analytical Hierarchy Process (AHP). Jurnal Ilmiah Teknik Industri, 10(1).

Rimantho, D., Fathurohman., Cahyadi, B., \& Sodikun. (2017). Pemilihan Supplier Rubber Parts Dengan Metode Analytical Hierarchy Process Di PT XYZ. Jurnal Rekayasa Sistem Industri, 6(2).

Sinulingga. (2015). Metode Penelitian. Medan: USU Press.

Sugiyono. (2012). Metode Penelitian Bisnis. Bandung: Alfabeta.

UNITEK Vol 12 No.1 Januari - Juni 2019

| p-ISSN 2089-3957 | e-ISSN 2580-2585 